\title{
Planejamento regional compartilhado em Minas Gerais: avanços e desafios
}

\author{
Shared regional planning in Minas Gerais: progresses and challenges
}

Nilo Bretas Junior', Helena Eri Shimizu²

RESUMO O objetivo do estudo foi analisar o planejamento regional em saúde de Minas Gerais, a fim de verificar os principais avanços e desafios. Foi realizado um estudo de caso do planejamento regional no período de 2007 a 2012. Analisaram-se os documentos: atas, relatórios e outros produzidos no processo de planejamento regional. Utilizaram-se como referencial teórico as categorias: direcionalidade, compartilhamento e prestação de contas. Verificouse que a direcionalidade tem sido prejudicada, pois as questões cotidianas se sobrepõem. $\mathrm{O}$ grau de compartilhamento das decisões mostrou-se elevado. Por fim, a petição e prestação de contas mostraram-se bastante frágeis.

PALAVRAS-CHAVE Planejamento em saúde; Gestão em saúde; Regionalização.

ABSTRACT The study aimed to analyze regional health planning in Minas Gerais in order to verify the main progresses and challenges. It was conducted a case study of regional planning in 2007-2012. Analyzed documents were: minutes, reports, and others produced in the regional planning process. Categories used as theoretical framework were: directionality, sharing and accountability. It was found that the directionality has been hampered because daily matters overlap. The degree of sharing of decisions was high. And, finally, the petition and accountability were quite fragile.

KEYWORDS Health planning; Health management; Regional health planning.

1 Universidade de Brasília (UnB) - Brasília, DF, Brasil. nilo@conasems.org.br

2 Universidade de Brasília (UnB), Departamento de Saúde Coletiva, Programa de Pós-Graduação em Saúde Coletiva - Brasília, DF, Brasil.

shimizu@unb.br 


\section{Introdução}

Entre os maiores desafios à construção do Sistema Único de Saúde (SUS) está a necessidade da regionalização solidária e cooperativa entre entes federados com a integração e o compartilhamento da gestão nas regiões de saúde por meio dos Contratos Organizativos de Ação Pública (Coap). Ganha centralidade, assim, a discussão a respeito do planejamento em saúde e como torná-lo instrumento de tomada de decisão por gestores nas regiões de saúde.

Pensadores, incluindo o argentino Mario Testa, apontaram críticas ao planejamento em saúde na América Latina, tais como: a omissão de aspectos políticos inerentes ao setor saúde, o subfinanciamento, a falta de coordenação dos serviços, a baixa capacidade de regulação do Estado, a incipiente capacidade de governo, alto nível de privatização dos sistemas de saúde, caracterizando-o como excessivamente tecnocrático, dominado pelo paradigma do planejamento normativo, fundamentado no pensamento econômico e administrativo (RIVERA; ARTMANN, 2012). Essa análise crítica enseja a defesa de um planejamento em saúde que extrapole a lógica econômica e apoie a formulação de políticas de saúde por meio da definição de estratégias, de diagnóstico setorial, de análise institucional, de programação regional e de monitoramento (PAIM; TEIXEIRA, 2006; RIVERA; ARTMANN, 2012; JESUS; TEIXEIRA, 2014).

Tal esforço consolida-se nas décadas de 1980 e 1990 no que se denominou planejamento estratégico, e vem sendo utilizado amplamente no setor saúde, inclusive no Brasil, por meio das três vertentes de pensamento que, partindo de referencial comum contrário à postura normativa, dão ênfase a aspectos distintos: o planejamento estratégico situacional de Carlos Matus, o pensamento estratégico de Mário Testa e o enfoque estratégico de saúde para todos de Bornechea, Trujillo e Chorny (RIVERA; ARTMANN, 2012). Diversos autores elaboraram críticas no sentido de seu aperfeiçoamento, desde a superação de obstáculos de aplicação metodológica até a necessidade de maior contextualização de seu uso, de maior abrangência de modelos explicativos de causalidades dos problemas de saúde e de incorporação de conteúdos comunicativos capazes de alavancar mudanças (RIVERA; ARTMANN, 2012; JESUS; TEIXEIRA, 2014).

Com a evolução da implementação do SUS, verifica-se um novo desafio de aperfeiçoamento, a construção regionalizada de políticas de saúde e com ação integrada entre entes federados autônomos (LIMA ET AL., 2012). Sem abrir mão da unicidade de princípios diretivos e organizativos do sistema, a atual política de construção do SUS, representado pelo Decreto $\mathrm{n}^{0} 7.508$ que regulamenta a Lei $\mathrm{n}^{0}$ 8.080, exige diversidade de estratégias e de ação para o enfrentamento dos problemas de saúde (BRASIL, 2011).

Assim, este estudo tem o objetivo geral de analisar o planejamento regional compartilhado em saúde de Minas Gerais desenvolvido no período de 2007 a 2012, a fim de verificar os principais avanços e desafios.

\section{Método}

Foi realizado um estudo de caso, da experiência de planejamento macrorregional desenvolvido em Minas Gerais pelo Conselho de Secretarias Municipais de Saúde do Estado (Cosems/MG), durante os anos de 2007 a 2012. A escolha metodológica justifica-se, pois o estudo de caso permite ao investigador aprofundamento em relação ao fenômeno estudado, revelando nuances singulares dos processos (YIN, 2005).

O Cosems/MG, partindo da análise estratégica do processo de regionalização estadual, de forma compartilhada com toda a sua diretoria e com a Secretaria de Estado da Saúde de Minas Gerais (SES/MG), pactuou na Comissão Intergestores Bipartite estadual (CIB/MG) sua corresponsabilidade 
na condução da implementação do processo de desenvolvimento do planejamento regional, com foco nas Macrorregiões de Saúde do Estado.

Assim sendo, o Cosems/MG, em função da necessidade de articular sua presença nas diversas regiões assistenciais, organizou-se em Cosems regionais, compondo o sistema de governança dessas regiões. Nas Microrregiões, participam as Comissões Intergestoras Regionais (CIR) em conjunto com regional da SES/MG e com participação de todos os secretários municipais de saúde da microrregião. Nas macrorregiões participam as Comissões Intergestoras Regionais Ampliadas (Cira), com participação das várias regionais da SES que estão no território. A quantidade de Cosems regionais difere da quantidade de micro ou macrorregiões por não se tratar de divisão assistencial, e sim de representação política dos municípios, divididos em polos de representação. Como resultados desse processo, foram definidos 25 Cosems Regionais.

Ademais, a partir de 2009, com o propósito de fortalecer o princípio da Regionalização Solidária e Cooperativa nos espaços de gestão regional, foi criado o Projeto Apoiador Cosems (MOTA, 2012). Neste Projeto, um profissional técnico acompanha as atividades de duas a seis microrregiões de saúde, e no mínimo um Cosems Regional ajuda na disseminação de informação, bem como provoca a mobilização regional dos gestores municipais para ações de fortalecimento da gestão em cada região.

Minas Gerais possui 22 apoiadores. Todos eles têm como principal atividade o apoio técnico aos Cosems regionais, subsidiando as ações regionais, a fim de enfrentar os problemas advindos da assimetria de informação, fragmentação institucional do Cosems e fortalecimento da capacidade técnica municipal, auxiliando no processamento técnico-político dos problemas e possibilidades de enfrentamento.
Tomando o Projeto Apoiador como forma de organização, o Cosems/MG desenvolveu a experiência de planejamento regional. Foram realizadas 125 oficinas macrorregionais, envolvendo apoiadores regionais do Cosems, secretários municipais de saúde e convidados das regionais da SES e algumas universidades. Também foram realizadas 7 oficinas centralizadas com apoiadores regionais do Cosems, equipe técnica de assessores do Cosems e, em alguns momentos, de dirigentes tanto do Cosems como da SES, para preparar as oficinas macrorregionais e para consolidar seus resultados. Essas oficinas resultaram em relatórios temáticos de planejamento e no alinhamento de estratégias em relatórios de pactuação nos fóruns intergestores CIR, Cira e CIB.

Dessa feita, foi realizada análise documental dos seguintes documentos produzidos no âmbito dos Cosems no período acima referido: 26 relatórios e 125 atas.

Para a análise, utilizou-se o referencial teórico do planejamento estratégico, em especial da Teoria das Macro-organizações e do Sistema de Direção Estratégica de Carlos Matus, com destaque para as seguintes regras: a Direcionalidade/Sistema de Conformação da Agenda do Dirigentee a Responsabilidade/ Sistema de Petição e Prestação de Contas por Resultados (MATUS, 1993).

Foi elaborada uma matriz analítica do planejamento regional integrado em saúde contendo três dimensões: a 'direcionalidade', que visou identificar se a configuração da agenda dos dirigentes de saúde confere direção ao processo de planejamento regional; a 'responsabilização', que consistiu em verificar a assunção das responsabilidades pactuadas e a prestação de contas no âmbito regional; e, por fim, o 'compartilhamento', que teve como propósito averiguar o processo de cogestão nas regiões de saúde. Cabe mencionar que essas categorias representam uma adaptação do trabalho de Lima (2003). 


\section{Resultados e discussão}

Em relação à categoria de análise da direcionalidade, os relatórios temáticos do planejamento regional trazem a missão claramente enunciada:

Construir um plano de ação que propicie a aglutinação dos municípios nas macrorregiões para uma ação coletiva e uma postura de co-gestão, com vistas à organização da rede interfederativa de forma complementar à organização microrregional. (BRASIL, 2008, P. 3).

Tal enunciado evidencia a clareza do papel dos gestores municipais, porém a análise dos relatórios de pactuação das CIRs e Ciras demonstra a predominância de discussões fragmentadas que, embora incidam sobre as ações planejadas, ocupam grande parte das agendas dos dirigentes a alocação de novos recursos ou as exigências de cumprimento das normas federais ou estaduais.

Essas agendas têm pautas que privilegiam os ritos da Comissão Intergestores Tripartite (CIT) e CIBs em detrimento dos problemas locais. Em um único mês, fevereiro de 2011, produziram-se 383 deliberações sobre temas pautados nessas instâncias, que foram encaminhados pelas diversas regiões para homologação na CIB/MG. Em julho de 2011, foram 130 , sendo que nesse mês foi um dos poucos momentos que se discutiram metas e indicadores de ações planejadas para as regiões.

Ainda quanto à categoria de análise da direcionalidade, as CIRs também apresentam diversidade de realidades. As Câmaras Técnicas, embora tenham sido regulamentadas por meio dos regimentos das CIRs em Minas Gerais, não funcionam como unidade de processamento prévio de problemas em todas as regiões. Tal situação pode ser observada em atas nas quais algumas discussões a respeito de um tema em pactuação têm opiniões emitidas diretamente pelos gestores, sem a exposição ou problematização nos âmbitos das CIRs e da Cira, o que acarreta em longa discussão e em alguns casos de postergamento das decisões.

Em realidade, observou-se que esses espaços de cogestão CIR e Cira, por vezes, têm sido conduzidos de modo burocrático e cartorial, sem um amplo debate por parte dos gestores envolvidos, o que pode resultar em baixa ou nenhuma repercussão nas práticas institucionais vigentes (VIANNA; LIMA, 2013).

Observa-se ainda que a CIR tem dificuldade para conferir direcionalidade à agenda de decisões, o que Matus (1996) denomina de Sistema de Configuração da Agenda do Dirigente. Este sistema contém o recurso mais crítico para os dirigentes: o tempo; além de ser responsável por manter o foco de atenção destes sobre aquilo que é prioritário.

Uma análise do Sistema de Agenda do Dirigente exige a verificação do quanto da sua atenção está voltado para assuntos e problemas relacionados com a missão, e não com problemas rotineiros e emergências e imprevistos. A preocupação de Matus (1996) com a racionalização da agenda do dirigente decorre da constatação de que, diante da enorme quantidade de problemas que normalmente surgem no cotidiano da gestão, há necessidade de se regular o tempo e o foco da atenção, caso não se deseje que a organização perca o rumo ante a demanda diária de problemas. As pressões que o dirigente sofre em sua gestão cotidiana contrariam o planejamento, a regulação racional do foco de atenção e o uso inteligente do tempo.

Desse modo, algumas questões são importantes para que a agenda de pactuações na CIR seja ordenada pela direcionalidade da missão de forma eficaz. É fundamental que a composição da pauta se baseie na missão enunciada e no plano de ação regional elaborado, no qual devem estar contidas as prioridades da gestão. Para isso, dois elementos devem ser destacados no Sistema de Direção Estratégica: a existência de uma Unidade de Processamento Técnico-Político e o entorno do dirigente (MATUS, 1996). A Câmara Técnica das CIRs deve ordenar a pauta em coerência 
com as prioridades do plano, e isso não parece ter ocorrido observando os relatórios de pactuação.

Alguns estudos feitos por Matus (1993; 1996) apontam que cerca de $10 \%$ do tempo do dirigente de países da América Latina são destinados a problemas importantes do governo. Mesmo sem poder realizar comparações entre seus estudos e a realidade das CIRs, pelas diferenças de metodologia e contexto situacional, percebe-se que o excesso de demanda oriunda das agendas Tripartite e Bipartite acaba por impedir esses momentos de planejamento e avaliação, fazendo com que a possibilidade de se perder o rumo aumente, uma vez que esse tipo de comportamento gera cegueira situacional (MATUS, 1996). Claro que demandas oriundas das agendas Tripartites e Bipartite sempre existirão; a questão é como orientá-las ou oportunizar a discussão das prioridades locais por meio dessa demanda externa, ao invés de simplesmente tentar respondê-las.

Quanto ao entorno dos dirigentes, é de crucial importância o trabalho desenvolvido pelos apoiadores regionalizados do Cosems e o papel cumprido pelo sistema de informação do Projeto Apoiador (PINHEIRO ET AL., 2013). Os apoiadores, orientados pelo escritório central do Cosems/MG, acabam direcionando os problemas que devem ou não serem dirigidos à pauta da CIR.

Quanto à categoria de análise do compartilhamento, verifica-se que ocorre o envolvimento de todos os gestores municipais no processo de discussão das questões relativas à região e também à forte presença dos mecanismos de comunicação do Cosems/MG. O fórum do Projeto Apoiador desenvolvido pelo Cosems tem grande número de informações relativas a essa comunicação com gestores municipais de saúde.

Tomando como referência o Postulado de Coerência de Mário Testa, que diz que a viabilidade de qualquer proposta irá depender da coerência entre três elementos fundamentais: os propósitos de governo, os métodos de planejamento e a organização (TESTA, 1987), o desafio pode ser traduzido em como estruturar as organizações - instâncias de gestão no SUS de forma coerente com os propósitos colocados. A implementação do SUS não foi acompanhada por mudanças nos métodos e estruturas das organizações de saúde (MENDES, 1996). O principal exemplo dessa rigidez de estruturas está diretamente relacionado com o espaço de atuação regional que são as instâncias regionais das SES, quase sem função, a não ser como repassadores de papel dos níveis centrais para os municípios e espaços de barganha política (SILVA; GOMES, 2013).

Quando Matus (1996) falou de descentralização, referiu-se a poder, capacidade de decisão, e não apenas de descentralização de responsabilidades. Nesse sentido, o apoio ao planejamento regional desenvolvido pelos Cosems contribuiu para fortalecer a construção da autonomia, do espaço regional. Entretanto, cabe ressaltar que não foram discutidos no espaço da CIR as responsabilidades de cada ente federado para com as ações planejadas, demonstrando grande fragilidade no processo de governança regional. Como consequência, não foram contempladas as decisões acerca do financiamento, da regulação e da gestão do trabalho.

É importante ressaltar que, com regulamentação da Lei no 8.080, de 1990, o desafio de realizar a integração regional dos sistemas municipais ganhou novo impulso. Na Carta de Maceió, elaborada em 2012 (CONASEMS, 2012), o Conselho Nacional das Secretarias Municipais de Saúde propõe uma agenda política para todos os 26 Cosems e todas as Secretarias Municipais de Saúde do Brasil em relação à regionalização que contempla: fortalecer a cogestão regional do sistema de saúde, rompendo o caráter excessivamente normativo do planejamento, possibilitando o planejamento ascendente e investindo na autonomia e capacidade de decisão das CIRs; reafirmar a direção única sobre prestadores em cada esfera de governo como um 
princípio inegociável no SUS e pré-condição para a governança regional da rede de atenção à saúde; pactuar uma política de financiamento equitativo que assegure o desenvolvimento de ações e serviços de saúde com base nas especificidades regionais, contribuindo com a redução das iniquidades no País.

Todavia, há que se considerar que entre os maiores desafios para a operacionalização do planejamento regional compartilhado está a questão do centralismo federal, sobretudo estimulado pela forma de repasses de recursos financeiros, e o gerenciamento centralizado da habilitação de serviços (SANTOS, 2015). Dessa feita, é fundamental que a CIR desenvolva o planejamento regional em seu sentido completo, com estabelecimento, especialmente de financiamento que extrapole os limites da população municipal.

Nesse sentido, não se pode conceber o processo de regionalização do sistema de saúde sem participação efetiva da esfera estadual, especialmente porque tem a responsabilidade de articulação e integração dos municípios. Ademais, tem a responsabilidade de apoio técnico e financeiros, que não podem ser genéricos e imprecisos, pois podem gerar sobreposições ou lacunas de atuação.

No que tange à categoria de análise responsabilização, dada a própria incipiência das CIRs, verifica-se grande fragilidade no Sistema de Petição e Prestação de Contas. Todas as 28 ações contidas no relatório consolidado de planejamento macrorregional têm responsabilidade atribuída a instituições ou ao Cosems/MG, e apenas 9 não contêm demandas a outras esferas de governo. $\mathrm{O}$ estatuto do Cosems/MG prevê a discussão e aprovação de relatórios de gestão do próprio Cosems, bem como dos Cosems regionais, de forma que essa dinâmica compõe o Sistema de Petição e Prestação de Contas. Também contribui para o Sistema de Petição e Prestação de Contas uma iniciativa do Cosems/MG denominada Prêmio Cosems em Ação. Este prêmio, criado em 2008, foi instituído para contemplar os Cosems regionais cujos gestores se empenharem em desenvolver atividades, visando à melhoria da qualidade da participação na implementação e proposição de políticas públicas no SUS em Minas Gerais. O prêmio objetiva incentivar e valorizar resultados dos Cosems regionais na melhoria da capacidade de aglutinação dos municípios sob sua jurisdição, na discussão da política estadual no contexto regional, na capacidade de trazer propostas para discussão no nível central, na agilidade na disseminação das informações, na maior interlocução com o escritório central do Cosems e no comparecimento nas reuniões ordinárias mensais do Cosems/MG. Os critérios de avaliação são publicados anualmente por edital, a avaliação é realizada por comissão constituída para essa finalidade e os resultados são amplamente divulgados. Pelo prêmio, é atribuído um valor financeiro ao Cosems regional que funciona como estímulo ao desenvolvimento do seu plano de ação.

Matus (1996) enfatiza que o alicerce do Sistema de Direção Estratégica do Planejamento Estratégico Situacional está no Sistema de Petição e Prestação de Contas. Segundo ele, somente por intermédio de mecanismos eficazes de petição e prestação de contas é possível considerar uma organização de alta responsabilidade, condição mínima para a implementação de ações descentralizadas e eficientes. No SUS, observa-se um déficit de responsabilidade, uma vez que a descentralização se deu de forma incompleta, por repasses de responsabilidades sem meios para serem cumpridas, com forte normatização centralizada de aspectos técnicos e de alocação de recursos financeiros e com competências vagas para a união e os estados: no que diz respeito à cooperação técnica e financeira (LIMA ET AL., 2012).

Em Minas Gerais, a única avaliação que consta das publicações diz respeito às expectativas colocadas pelos gestores no início do processo em 2007. Dos 19 objetivos do planejamento regional, apenas 7 não tiveram 
respostas, mas acordou-se em estabelecer estratégias para respondê-las. São eles: construir um sistema de planejamento integrado; facilitar o diálogo com o mundo jurídico e com o poder judiciário; estabelecer complementariedade com o planejamento microrregional (Cosems e SES estabeleceram a homologação na CIB das pactuações, embora precise ser aperfeiçoado); aperfeiçoar o planejamento intramunicipal, utilizando o planejamento regional; desenvolver cultura de planejamento como instrumento de gestão; implementar o sistema de planejamento em todos os níveis da atenção; unificar o sistema de planejamento, rompendo com fragmentações de programas.

Fica claro que para responder a esses problemas é necessário aperfeiçoar os instrumentos de planejamento e a sincronicidade dos processos intramunicipal, regional, estadual e nacional (BRASIL, 2011; 2012A). Os relatórios de gestão, por exemplo, precisam dialogar com as estratégias planejadas e necessitam de critérios para sua avaliação, para muito além do cumprimento da exigência legal de serem apresentados. Por isso, os resultados precisam ser pactuados e conhecidos por todos os membros da CIR. O estabelecimento de objetivos, metas, indicadores e instrumentos para verificá-los ampliam a responsabilidade de todos.

No entanto, os indicadores de avaliação pactuados na época do estudo, hoje pactuados pela Resolução CIT n ${ }^{0} 5$ (BRASIL, 2012B), que informam as prioridades nacionais, por exemplo, dizem respeito muito mais a processos e meios, além de estarem fortemente associados à cultura de controle e repasse de recursos financeiros, dado o entendimento que o dinheiro é federal enquanto deveria ser considerado nacional. Isso resulta em uma visão um tanto quanto taylorista da administração pública, ao não se preocupar com os resultados.

A Lei Complementar 141, de 2012, que regulamenta a Emenda Constitucional 29, corrobora este fato ao fortalecer o Relatório Anual de Gestão (RAG) e os mecanismos de publicização da prestação de contas como os instrumentos para o sistema de planejamento. Verificando a situação dos RAGs em Minas Gerais à época do estudo, apenas em 3,28\% dos municípios a informação da existência ou não do RAG não foi encontrada, embora não seja possível verificar se as ações referentes à região de saúde estão contidas neles. O próprio Ministério da Saúde (MS) não apresenta regularidade nos instrumentos do sistema de planejamento ao longo da história do SUS. O Plano Nacional de Saúde para o período 2008 a 2011 só foi apresentado e discutido pelo Conselho Nacional de Saúde em outubro de 2009.

Esses fatos vão ao encontro de duas observações importantes de Matus (1996), para aumentar a responsabilidade do sistema de saúde. A primeira e mais importante é a que a prestação de contas deve ser feita publicamente, ou difundida até a população. A divulgação realizada pelas páginas da Internet do MS, da SES/MG, do Cosems/MG e de vários municípios mostra o empenho nessa direção. Também é visível o esforço que o Cosems/MG vem fazendo ao desenvolver atividades de educação permanente voltadas para a cultura da prestação de contas públicas. Tendo em vista não haver no SUS uma instância de controle social regional, até por não se constituir a região em ente federado, é fundamental estabelecer mecanismos de articulação interconselhos, para que a alta responsabilidade a que Matus se refere possa ser característica da organização do SUS, ampliando a visibilidade da gestão no âmbito do sistema regional de saúde.

O segundo ponto que vai ao encontro das recomendações de Matus (1996) diz respeito à regularidade da prestação de contas. A regularidade contribui para gerar uma cultura de responsabilidade, pois cria hábito naqueles que devem prestar contas das suas ações a atuarem com mais visibilidade em seus atos, sendo que a Lei 141 determina que a programação anual de saúde, que inclui ações regionais, deva também ser 
submetida previamente aos conselhos de saúde (BRASIL, 2012A).

Na Lei 141, estão previstas punições, como suspensão de receitas tributárias dos fundos de participação dos estados e municípios, suspensão de transferências voluntárias da união, entre outras, embora os mecanismos da aplicação das punições às responsabilidades compartilhadas nas regiões de saúde ainda precisem ser melhor esclarecidas, da mesma forma às responsabilidades da União. Segundo Matus (1996), em um sistema de alta responsabilidade, como deve ser o SUS, todos devem se sentir responsáveis por prestar contas a todos.

Os planos de ação regionais construídos e pactuados precisam ser aprimorados tanto para diminuir a responsabilização difusa já mencionada, quanto para objetivar mais prioridades, metas, indicadores e, principalmente, quanto ao que Matus (1993) formulou como momento estratégico e momento tático operacional.

Segundo Campos (1990), a possibilidade de tornar a administração pública brasileira $a c$ countable estaria diretamente relacionada com as chances das seguintes ocorrências, as quais, como podem ser verificadas, guardam certa interdependência e estão diretamente relacionadas com a democracia: a) organização dos cidadãos para exercer o controle político do governo; b) descentralização e transparência do aparato governamental; e c) substituição de valores tradicionais por valores sociais emergentes. Tem-se no País uma democracia muito nova, e esse exercício da democracia ainda irá desenvolver em muito as organizações públicas e a relação com a sociedade.

O Centro Latino-Americano de Administração para o Desenvolvimento (Clad) alertou para o fato de que a realização do valor político da accountability depende de dois fatores: um deles é o desenvolvimento da capacidade dos cidadãos de agir na definição das metas coletivas de sua sociedade, já que uma população indiferente à política inviabiliza tal processo; o outro é a construção de mecanismos institucionais que garantam o controle público das ações dos governantes ao longo de todo o seu mandato. Ainda se está 'engatinhando' nessa prática no SUS, embora a saúde seja a política pública com maior participação da população no território nacional.

\section{Conclusões}

A Teoria das Macro-organizações e o Sistema de Direção Estratégica elaborados por Carlos Matus (1994) foram muito pertinentes para a realização da análise do planejamento regional em Minas Gerais. Isso porque o espaço de análise correspondia, de fato, a uma Macroorganização. Esse referencial permitiu uma análise aprofundada baseada em grandes categorias de análise do planejamento como instrumento de gestão. Possibilitou ainda a verificação do funcionamento do sistema de planejamento e como aplicar seus conceitos em prol da cogestão regional do sistema.

Quanto à capacidade da agenda dos dirigentes de conferir direcionalidade ao processo de planejamento regional, verificou-se que, embora as agendas ainda sejam fragmentadas, as discussões são potencializadoras da participação dos gestores nas CIR.

No que tange ao compartilhamento das decisões na região de saúde, pode-se afirmar que é ampla a participação dos gestores e que os mecanismos de comunicação do Cosems são bastante eficazes para dar visibilidade aos processos atinentes ao planejamento regional. Contudo, é preciso destacar que a CIR prescinde de condições para exercer governança, tanto política como executiva, que ainda se encontram bastante limitadas.

Em relação à prestação de contas das ações pactuadas, a experiência do Cosems/MG, inconclusa porque ainda em desenvolvimento, apresenta essa falha, pois não foram identificados mecanismos de avaliação de resultados, tal como sugerido pela Teoria das Macro-organizações. 
O processo de planejamento compartilhado em Minas Gerais logrou alguns avanços, sobretudo a criação de espaços de cogestão que visam à discussão dos problemas e necessidades locorregionais. Todavia, é preciso fortalecer a direcionalidade do planejamento regional, que requer ações de monitoramento e avaliação, que devem contar inclusive com a participação mais direta da população.
Além disso, é necessário ressaltar a importância de fortalecer os espaços de controle social.

Por fim, em relação à experiência de planejamento compartilhado de Minas Gerais, acredita-se que pode, tanto pelos seus aspectos mais inovadores e positivos quanto pelas deficiências identificadas, ajudar a aprimorar o processo de planejamento regional no País.

\section{Referências}

BRASIL. Oficinas de Planejamento Regional PlanejaSUS. COSEMS MG, Belo Horizonte, v. 1, n. 1, p. 1-4, abr./ago., 2008.

Decreto $\mathrm{n}^{\mathrm{o}} 7508$, de 28 de junho de 2011. Regulamenta a Lei nº 8.080, de 19 de setembro de 1990, para dispor sobre a organização do Sistema Único de Saúde - SUS, o planejamento da saúde, a assistência à saúde e a articulação, e das outras providências. Diário Oficial [da] União, Brasília, DF, 2011. Disponível em: <http://www.planalto.gov.br/ccivil_03/_ato20112014/2011/decreto/D7508.htm>. Acesso em: $11 \mathrm{dez}$. 2015.

Lei Complementar $\mathrm{n}^{\mathrm{o}}$ 141, de 13 de janeiro de 2012. Regulamenta o $₫ 3^{\circ}$ do art. 198 da Constituição Federal para dispor sobre os valores mínimos a serem aplicados anualmente pela União, Estados, Distrito Federal e Municípios em ações e serviços públicos de saúde; estabelece os critérios de rateio dos recursos de transferências para a saúde e as normas de fiscalização, avaliação e controle das despesas com saúde nas 3 (três) esferas de governo; revoga dispositivos das Leis nos 8.080 , de 19 de setembro de 1990, e 8.689, de 27 de julho de 1993; e dá outras providências. Diário Oficial [da] União, Brasília, DF, 2012a. Disponível em: <http://www.planalto.gov.br/ccivil_03/leis/LCP/Lcp141.htm>. Acesso em: 11 dez. 2015.

Ministério de Saúde. Resolução CIT n ${ }^{\circ} 5$, de 19 de janeiro de 2012. Dispõe sobre as regras do processo de pactuação de Diretrizes, Objetivos, Metas e Indicadores para os anos de 2013-2015, com vistas ao fortalecimento do planejamento do Sistema Único de Saúde (SUS) e a implementação do Contrato Organizativo da Ação Pública da Saúde (COAP). Diário Ofical [da] União, Brasília, DF, 2012b. Disponível em: <http://bvsms.saude.gov.br/bvs/saudelegis/cit/2013/ res0005_19_06_2013.html>. Acesso em: 5 dez. 2015.

CAMPOS, A. M. Accountability: quando podemos traduzi-la para o português? Rev Adm Pub, Rio de Janeiro, v. 24, n. 2, p. 30-50, fev./abr., 1990.

\section{CONSELHO NACIONAL DAS SECRETARIAS} MUNICIPAIS DE SAÚDE (CONASEMS). Carta de Maceió. Brasília, DF, 2012. Disponível em: <http://www. conasems.org.br/site/index.php/comunicacao/ultimas-noticias/2373-carta-de-maceio>. Acesso em: 17 jan. 2013.

JESUS, W. L. A.; TEIXEIRA C. F. Planejamento governamental em saúde no estado da Bahia, Brasil: atores políticos, jogo social e aprendizado institucional. Cienc. saude coletiva, Rio de Janeiro, v. 19, n. 9, p. 3839-3848, set. 2014.

LIMA, J. C. Gestão estratégica de sistemas de saúde: estudo de caso de uma região de saúde à luz da teoria das macroorganizações. 2003. 182 f. Dissertação (Mestrado em Saúde Pública) - Escola Nacional de Saúde Pública, Fundação Oswaldo Cruz, Rio de Janeiro, 2003.

LIMA, L. D. et al. Regionalização e acesso à saúde nos estados brasileiros: condicionantes históricos e político-institucionais. Cienc. saude coletiva, Rio de Janeiro, v. 17, n. 11, p. 2881-2892, nov. 2012. 
MATUS, C. Política, planejamento \&t governo. Tomos I e II. Brasília, DF: Instituto de Pesquisa Econômica Aplicada, 1993.

El Metodo PES, Reingenieria Publica y La Teoria de Las Conversaciones: Trabas y Problemas. Santa Fé, Colômbia: Fondo Editorial Altadir, 1994.

Adeus, senhor presidente: Governantes

Governados. São Paulo: Fundap, 1996.

MENDES, E. V. Uma agenda para a saúde. São Paulo: Hucitec. 1996.

MOTA P. S. A contribuição do projeto apoiador do COSEMS/MG no espaço de gestão regional de saúde do Estado de Minas Gerais no período de 2009 a 2011. 2012. 142 f. Dissertação (Mestrado em Administração Pública) - Escola de Governo Dr. Paulo Neves de Carvalho, Fundação João Pinheiro, Belo Horizonte, 2012.

PAIM, J. S.; TEIXEIRA, C. F. Política, planejamento e gestão em saúde: balanço do estado da arte. Rev. Saude Publica, São Paulo, v. 40, n. esp., p.73-78, ago. 2006.

PINHEIRO, R. et al. Apoiadores regionais: uma experiência brasileira. Rio de Janeiro: CEPESC/IMS/UERJ/ COSEMS RJ/OPAS, 2013.
RIVERA, F. J. U; ARTMANN, E. Planejamento e gestão em saúde: conceitos, história e propostas. Rio de Janeiro: Fiocruz, 2012.

SANTOS, L. Regionalização em Debate. São Paulo. Cadernos COSENS/SP, São Paulo, v. 4, n. 1, p. 54-59, 2015.

SILVA, E. C.; GOMES, M. H. A. Impasses no processo de regionalização do SUS: tramas locais, Saude soc, São Paulo, v. 22, n. 4, p. 1106-1116, dez. 2013.

TESTA, M. Estrategia, coherencia y poder en las propuestas de salud: parte I. Cuadernos médico sociales, Rosario, v. 38, n. 4, p. 3-24, mar. 1987.

VIANNA, R. P.; LIMA, L. D. Colegiados de Gestão Regional no estado do Rio de Janeiro: atores, estratégias e negociação intergovernamental. Physis, Rio de Janeiro, v. 23, n. 4, p. 1025-1049, out./dez., 2013.

YIN R. K. Estudo de caso: planejamento e métodos. 3. ed. Porto Alegre: Bockman, 2005.

Recebido para publicação em maio de 2015

Versão final em agosto de 2015

Conflito de interesses: inexistente

Suporte financeiro: Conselho Nacional de Desenvolvimento

Científico e Tecnológico (CNPq) 